\title{
Formação de professores para o século XXI: dimensões de uma crise vivenciada
}

Geni Rosa Duarte*

\section{RESUMO}

Este artigo propõe-se a analisar algumas mudanças nos debates historiográficos mais recentes, que afetam o ensino de História e a definição do papel do professor, como uma crise. Torna-se difícil ao professor de História incorporar essas mudanças historiográficas no contexto da sala de aula e no uso de materiais didáticos. Entretanto, essas mudanças podem apontar alguns caminhos para a formação de professores no século XXI.

Palavras-chave: crise, historiografia, ensino de História, formação de professores de História.

A proposta deste artigo é: pensar a formação e, consequentemente, as margens de atuação profissional do professor de história no século XXI.

Não se trata de um exercício de futurologia, passível de ser feito a partir de um referencial ficcional, por exemplo. Aliás, isso foi feio pelo escritor Lloyd Bigle Jr., num conto publicado há algumas décadas numa antologia de ficção científica, no qual ele imaginou a situação de um professora de literatura inglesa, Mildred Boltz, que volta à terra após uma longa temporada de trabalho fora dela, numa escola do planeta Marte, então já colonizado e ocupado pela Terra. Voltando, ela penetra num sistema escolar que havia sofrido uma verdadeira revolução pedagógica: as aulas face a face haviam sido totalmente substituídas por um ensino processado via TV. A profissão de professor tornarase muito lucrativa, mas tinha geralmente duração muito curta, pois as pressões para manter um determinado número de alunos com as TVs ligadas naquela aula - não necessariamente atentos - eram muito grandes, o que levava os

\footnotetext{
* Professora da Universidade Estadual do Deste do Paraná (UNIOESTE), campus de Marechal Cândido Rondon. E-mail: rosaduarte@unioeste.br.
} 
profissionais a lançar mão de expedientes não exatamente pedagógicos - de palhaçadas a strip tease. É claro que a professora, já de certa idade, com bastante experiência, não consegue dar conta do recado e, na iminência de ser despedida, resolve, com o auxílio de alguns amigos, recuperar aquilo que seria o fundamental no ensino: o contato efetivo professor/aluno, numa relação efetiva de aprendizagem. E é justamente esse processo de trocas que sugere 0 nome do conto: Maneira doida de lecionar. ${ }^{1}$

A referência a esse conto não é aleatória; ela demarca a posição de que parto nesse debate, mesmo contrariando as vozes que apontam a necessidade urgente de acesso por parte de professores e alunos a novas tecnologias, considerando "a emergência de novos padrões de sociabilidade e colaboração digitais [...] assim como novas formas de entretenimento em rede", conforme enfatiza artigo publicado esta semana na Folha de São Paulo (GIORDAN, 2005, p. 3).

Não creio que sejam esses os parâmetros que devemos considerar ao pensar o ensino de história e o processo de formação dos professores, uma vez que nenhuma revolução digital pode dar conta das opções políticas realizadas cotidianamente quando se define o que e como ensinar a nossa disciplina. Não se trata, portanto, da necessidade de modernizar simplesmente o ensino de história, com o uso de novos recursos ou o acesso a novas formas de conhecimento, mas de refletir sobre o próprio sentido de se ensinar história no século XXI.

Para tanto, proponho que pensemos em algumas mudanças vivenciadas direta ou indiretamente pelos profissionais de história nas últimas décadas, que se refletem diretamente no cotidiano da sala de aula. Costuma-se culpar o professor pela crise vivenciada no ensino, que faz com que tantos alunos se desinteressem pela questão da aprendizagem - ou então a metodologia adotada, baseada na repetição de conceitos muitas vezes limitada ao livro didático. Acredito que não seja possível mudar a forma de transmissão dos conhecimentos, sem se discutir antes sobre aspossibilidades e limites do próprio conbecimento com que se lida.

1 Antologia de Ficção Científica n ${ }^{\circ}$ 3. Porto Alegre, Editora Globo, 1973, p. 257-285 
A crise a que me refiro, portanto, não tem dimensões restritas ao espaço escolar. Ela atingiu os próprios fundamentos da constituição da história enquanto disciplina: na medida em que se abriam novos campos para a investigação histórica, caía por terra a perspectiva de que esses conhecimentos produzidos constituíam um conjunto que contemplava por si mesmo os critérios de validade universal e de absoluto. Caíam por terra as certezas advindas dos referenciais positivistas de neutralidade e objetividade científica.

Para o professor de história, isso representava a quebra daquelas certezas advindas de uma organização dos fatos em linhas do tempo auto-explicativas, constituindo referenciais para se pensar passado e presente. Mas quebrava-se também a crença numa perspectiva histórica formulada no campo do marxismo ortodoxo, centrado na percepção de leis da história e num determinismo unidirecional entendido como necessário e inevitável.

Essa dupla quebra fez com que 0 chão sobre o qual tradicionalmente se assentava todo o trabalho do professor fosse tirado. Para que servia, então, ensinar história? 0 que desenvolver com esse ensino? Quais os parâmetros através dos quais esse trabalho deveria ser redimensionado?

Tradicionalmente, o ensino de história revestiu-se de uma importância significativa tendo em vista a formulação de objetivos definidos a partir de instâncias que não o próprio professor. Desde as primeiras décadas de constituição do Estado brasileiro, propunha-se que esse ensino participasse da construção de uma identidade nacional que impedisse o esfacelamento territorial.

Posteriormente, propôs-se que ele fosse capaz de formar cidadãos que, pelo sentimento de identificação com vultos nacionais, se sentissem participantes de uma mesma cultura e de uma mesma tradição. A essa perspectiva de homogeneização, se acresceu a de nacionalização, no momento em que se via o estrangeiro enquanto ameaça à ordem constituída.

Tais objetivos direcionavam não só a escolha dos conteúdos, mas até mesmo a forma como eles eram transmitidos. Daí a valorização das datas, ligadas às comemorações enquanto repetições ritualizadas dos eventos; daí 0 próprio encadear dos acontecimentos numa linha do tempo apontando essencialmente para o progresso como meta e para o cumprimento de um destino reservado à pátria. Isso tudo deu ao conjunto de conteúdos escolares de história uma permanência bastante significativa, fazendo com que as mudanças fossem simplesmente de ênfase nesta ou naquela direção. 
Essa perspectiva de ensino de história valia até mesmo para os anos do regime militar, através da imposição feita dos conteúdos cívicos por intermédio dos Estudos Sociais, OSPB e Educação Moral e Cívica. Exercer o controle sobre o trabalho do professor tornava-se uma questão de segurança nacional, definida a partir do conceito de segurança interna, que trazia a definição clara de inimigos internos, aqueles que semeariam o dissenso, sem contribuir para o projeto de desenvolvimento configurado nos projetos levados a cabo pelo governo militar. Nas palavras do Marechal Castelo Branco, definindo o conceito:

Compreende, por assim dizer, a defesa global das instituições, incorporando, por isso, os aspectos psicossociais, a preservação do desenvolvimento e da estabilidade política interna; além disso, o conceito de segurança, muito mais explicitamente que o de defesa, toma em linha de conta a agressão interna, corporificada na infiltração e na subversão ideológica, até mesmo nos movimentos de guerrilha, formas hoje mais prováveis de conflito que a agressão externa (grifos meus)².

Essa conceituação é fundamental, ainda mais considerando que nesses anos vivia-se um processo de pressão para expansão do ensino secundário, o que viria a se concretizar pouco depois com a instalação da escola de oito anos com a eliminação do exame de admissão. Ao mesmo tempo, o processo de controle e distribuição do livro didático agia no sentido de homogeneizar "corações e mentes", impedindo a autonomia do professor, vista muitas vezes como desagregadora. Essa era uma das medidas no sentido de impedir a eclosão de "tensões e lutas", e assegurar o consenso, portanto, tornava-se fundamental. A proposta de formação de professores através das licenciaturas curtas em Estudos Sociais, desqualificando, muitas vezes, até mesmo os limites mais largos dos licenciados em História e Geografia, caminhava nessa direção.

Nesse sentido, a adesão de parte do professorado a uma perspectiva de ensino "etapista", calcada no marxismo ortodoxo, configurado nos chamados "modos de produção", pode ser lida como uma tentativa de resistência exatamente a essa imposição de conteúdos, de práticas pedagógicas e de objetivos definidos a partir das instâncias estatais. Contrapondo-se à perspectiva de

2 Aula inaugural dos cursos de 1967 da Escola Superior de Guerra, proferida pelo Mal. Humberto de Alencar Castelo Branco, então presidente da República (mimeografado) 
valorização de heróis nacionais, em especial aqueles ligados com o conceito de defesa do território - Duque de Caxias, por exemplo - essa perspectiva reaafirmava a possibilidade de atuação de sujeitos coletivos - o proletariado, no caso. Ao mesmo tempo, isso representava a quebra da cronologia tradicional, valorizando os aspectos interpretativos sobre os descritivos. Mais: mesmo os aspectos deterministas presentes nas propostas sinalizavam possibilidades de mudanças, de rupturas, e de que as coisas não ficariam sempre exatamente como tinham sido impostas. Mesmo fora de uma visão mais "militante", essa perspectiva pressupunha que as mudanças eram possíveis, e certamente seriam viabilizadas.

A historiografia se abria para a investigação de novos temas, de novos problemas. Incluía, entre suas preocupações, a investigação de dimensões do cotidiano, abrindo-se para outras dimensões da vida social até então ignoradas. Procurava dar conta de silenciamentos e exclusões, trazendo à cena questões de grupos minoritários e de projetos não vencedores.

Significativamente, começam a emergir preocupações com a preservação da memória histórica no seio de alguns movimentos sociais que se fizeram presentes no período. Projetos como a formação de um Centro Cultural do Trabalhador, no local onde se situava a antiga fábrica de cimento Portland Perus, fazendo referência à greve de sete anos desencadeada a partir de 1962, começaram a ser articulados. Muitas escolas de ensino fundamental da região iniciaram também projetos articulados a essas iniciativas. ${ }^{3}$

Nos anos 1980, começaram a ser apresentadas propostas pedagógicas, a partir dos sistemas estaduais e municipais de ensino, visando redimensionar a relação ensino / aprendizagem. Não podemos considerar tais propostas simples reflexos da discussão historiográfica produzida na academia, uma vez que a escola não sofreu passivamente essas consequiências. Mas torna-se evidente que nos anos 1980 intensificavam-se os sinais da crise a que já nos referimos.

Afastando-se, portanto, de uma perspectiva de um ensino voltado para a homogeneidade, seja da constituição de uma identidade nacional, seja de um

3 Caso da Escola Municipal de Ensino Fundamental Cândido Portinari, cuja experiência nos anos de 1990 foi objeto de comunicação por Maria Helena Bertolini Bezerra no XXI Simpósio Nacional da ANPUH, realizado em 2001, em Niterói, RJ.Nessa mesma região outras experiências também foram desenvolvidas, atingindo outras escolas públicas. 
processo de nacionalização ou de disciplinarização de amplos setores da população, muitas das propostas colocavam em cheque, em primeiro lugar, a separação entre planejamento e execução. Caía por terra, portanto, a possibilidade de uma definição a priori dos conteúdos de história a serem ensinados, ou seja, de um programa único. A margem de liberdade que isso propiciou, ao contrário do que se poderia esperar, não foi vivenciada sem conflitos pelos professores, uma vez que ela colocava em cheque os próprios limites da sua formação.

Em decorrência disso, propostas curriculares como a apresentada pela CENP/ SP nos anos 80, que propunha para os professores de história um trabalho com dimensões do presente vivenciado enquanto espaço de tensões e conflitos, deixando margem para 0 indeterminado, 0 indefinido, o diferenciado, - no termos com que ela foi apresentada -, foram recebidas com muitas dúvidas e até mesmo com uma larga margem de rejeição. Além disso, essa proposta colocava em questão os lugares da produção historiográfica, apontando para a possibilidade de que ela emergisse a partir de outros espaços - sindicatos, associações, movimentos sociais, etc. A escola, nesse caso, seria um dos locais onde tal possibilidade poderia se concretizar, uma vez que o ensino deveria englobar vivência e reflexão, não se constituindo num corpo de conhecimentos já prontos para serem transmitidos a partir de objetivos prédeterminados.

A proposta foi rejeitada por setores conservadores, mas sua discussão evidenciou uma crise no seio dos professores, aos quais ela se dirigia. Ela propunha uma quebra exatamente na perspectiva da totalidade, sugerindo que se trabalhasse com o fragmentado, com 0 diferenciado. Pressupunha ainda uma aproximação entre conhecimento científico e conhecimento de senso comum, ou, pelo menos, a quebra dos rígidos limites separando essas duas formas. Com isso, ela redimensionava exatamente aquilo que Marilena Chauí denominava de discurso competente, quebrando regras de inclusão e exclusão de antemão definidas, apontando a existência de saberes muitas vezes marginalizados a partir das relações de poder.

0 trabalho proposto e realizado por Conceição Cabrini com $5^{\mathrm{a}}$. série numa escola da periferia da Grande São Paulo, entre 1983 e 1984, dentro do projeto articulado por um grupo de professores da PUC SP (CABRINI, 1985), tinha como questão central a possibilidade de "permitir tanto ao aluno como ao professor uma 
reflexão sobre sua historicidade", captando os interesses da história vivida, "sem cair num grotesco presentismo, num mero estudo do meio, ou numa simples 'apologia'd do cotidiano"(CABRINI,1985, p. 82).

Essa proposta colocava em questão também a questão da formação do professor para 0 ensino fundamental.Como deveria ser o professor formado para articular as relações entre o saber acadêmico e o saber transmitido em sala de aula? Nos termos colocados pelos próprios formuladores da proposta:

Deve ser alguém que domine o processo de produção do conhecimento histórico; que seja alguém que saiba se relacionar com o saber histórico já produzido e que, finalmente, seja alguém capaz de encaminhar seus alunos (sejam eles do $1^{\circ}, 2^{\circ}$ ou $3^{\circ}$ graus) nesses mesmos caminhos da produção e da relação crítica com 0 saber (CABRINI, 1985, p. 85).

Entretanto, não poderia me furtar de me referir a outros direcionamentos para a formação docente, propostos pelo governo federal a partir das Diretrizes e Parâmetros para o ensino fundamental e médio nos últimos anos, que vão numa direção oposta a essas já referidas anteriormente.

Constatando o crescimento significativo da rede pública no que se refere ao ensino médio, especialmente nos cursos noturnos, e pensando esse nível de ensino como terminalidade, os Parâmetros Curriculares Nacionais - Ensino Médio (PCNEM) propostos direcionam a estruturação dessa etapa final da educação básica, estabelecendo a ligação entre as expectativas sociais para 0 egresso desse ensino e o mundo da escola.

Os objetivos para o ensino médio, dessa forma, são apresentados pelo documento vinculados à compreensão das exigências que o mundo do trabalho e a moderna sociedade tecnológica colocam à educação. Desligando-se da visão de formação profissional visando preparar o aluno para a inclusão social via profissionalização, o documento citado ressalta que a revolução tecnológica em curso e seus desdobramentos nas áreas da produção e da informação colocam como exigências à escola "o desenvolvimento das competências cognitivas e culturais para o pleno desenvolvimento humano [que] passa a coincidir com o que se espera na esfera da produção"(PCNEM, p. 12). 
0 domínio de tais competências torna-se também condição para 0 exercício da cidadania, mesmo que ele não assegure "uma bomogeneização das oportunidades sociais" ou seja: nem todos terão emprego garantido, mas todos se definirão quanto à sua empregabilidade.

As competências requeridas para a inserção - real ou virtual - no mundo do trabalho relacionam-se aos resultados trazidos pela globalização econômica, a qual,

ao promover o rompimento de fronteiras, muda a geografia política e provoca, de forma acelerada, a transferência de conhecimentos, tecnologias e informações, além de recolocar as questões da sociabilidade humana em espaços cada vez mais amplos". Como consequiência, "a velocidade do progresso científico e tecnológico e da transformação dos processos de produção torna o conhecimento rapidamente superado, exigindo-se uma atualização contínua e colocando novas exigências para a formação do cidadão (PCNEM, p. 14).

As competências, portanto, dizem respeito fundamentalmente à capacidade de fazer frente às contínuas mudanças e à contínua superação dos conhecimentos, requerendo-se dos indivíduos que saibam como ter acesso a novas fontes de informação. Prioriza-se, nos termos do documento, "o domínio dos próprios instrumentos do conhecimento, considerado como meio e como fim".(PCNEM, p. 16) numa direção que garanta a possibilidade de "buscar informação, gerar informação, usá-la para solucionar problemas concretos na produção de bens ou na gestão e prestação de serviços" (PCNEM, p. 18).

Torna-se necessário, segundo o documento, investir na formação dos docentes, "uma vez que as medidas sugeridas exigem mudanças na seleção, tratamento dos conteúdos e incorporação de instrumentos tecnológicos modernos, como a informática" (PCNEM, p. 13). Portanto, a primeira necessidade apontada, comum a todos, configura-se no domínio de novas tecnologias. A estruturação da área de História, no interior de um conjunto chamado Ciências Humanas e suas tecnologias, direciona o processo de formação e de qualificação dos professores, evidenciando que competências docentes são desejáveis.

Dessa forma, a própria organização dos conteúdos possui um viés pragmático muito acentuado. Os conhecimentos são escolhidos, retomados e 
utilizados para dar conta de determinadas situações. Nos termos do documento: “...a interdisciplinaridade deve ser compreendida a partir de uma abordagem relacional, em que se propõe que, por meio da prática escolar, sejam estabelecidas interconexões e passagens entre os conhecimentos através de relações de complementaridade, convergência ou divergência" (PCNEM, p. 22). Do que se conclui que a palavra conbecimentos (utilizada no plural, no texto citado) pode ser substituída pela palavra informação.

No que consiste a docência, nessa perspectiva? Como a matéria prima proposta pelo ensino - conhecimentos, informações - ao professor compete, basicamente, garantir o acesso dos alunos a esse conjunto. Como? Através da incorporação, na sua prática, dos processos envolvidos nas novas tecnologias. 0 professor torna-se, então, um articulador entre os alunos, tabula rasa despidos de qualquer experiência significativa, e o conjunto de conhecimentos já dados.

Dentre os objetivos propostos para a área de Ciências Humanas, traduzidas nas competências esperadas, propõem-se: compreensão da sociedade, sua gênese e transformação, e das instituições sociais, políticas e econômicas, bem como do processo de ocupação dos espaços, utilizando tais conhecimentos para a discussão e resolução de situações novas - e vale a pena reproduzir os demais objetivos ou competências:

Entender os princípios das tecnologias associadas ao conhecimento do indivíduo, da sociedade e da cultura, entre as quais as de planejamento, organização, gestão e trabalho de equipe, e associá-los aos problemas que se propõem resolver"; "entender 0 impacto das tecnologias associadas às Ciências Humanas sobre sua vida pessoas, os processos de produção, o desenvolvimento do conhecimento e a vida social"; "entender a importância das tecnologias contemporâneas de comunicação e informação para planejamento, aplicar as tecnologias das Ciências Humanas e Sociais na escola, no trabalho e em outros contextos relevantes para sua vida (PCNEM, p 15-16).

Ou seja, qual o papel do professor nesse processo? 0 ensino proposto visa simplesmente entender o projeto já dado, pelo qual o aluno é introduzido nesse mundo, origem e finalidade do próprio processo educativo. Conseqüentemente, o professor nada mais é do que um intermediário, alguém que traduz os 
objetivos e as etapas do processo, para que ele seja mais bem incorporado pelos seus discípulos.

Temo ter voltado ao meu ponto de início, ou seja, a história da professora marciana que volta à Terra. Consequentemente, podemos perceber que, nos nossos dias, ampliam-se as dimensões da crise a que nos referimos logo no início, uma vez que a atuação do professor se complementa com políticas educacionais "privilegiadoras" de determinadas ações e "ignoradoras" de outras demandas. Portanto, a crise vivenciada é multidimensional, não podendo ser resolvida a partir de soluções tomadas algures.

Contrapondo soluções como as apontadas acima, via parâmetros nacionais, à crise vivenciada apontada neste texto, podemos concluir que soluções "apaziguadoras" não serão, de maneira nenhuma, adequadas, e muito menos bem-vindas. Há uma oposição fundamental entre a demanda de um ensino que aponta exatamente para o compromisso com o diferenciado, e que se distancia muito da solução homogeneizadora apontada pelas esferas oficiais.

A partir dessas considerações, , gostaríamos de apontar algumas questões que certamente estarão presentes na atuação profissional do professor de história no século XXI.

A primeira delas decorre da constatação de que a vivência das crises, por parte dos professores, foi muitas vezes sentida como uma inadequação da formação profissional. Ou seja, torna-se muito difícil responder aos novos desafios a partir de uma formação tradicional, que valorizava exatamente aquilo que no presente deve ser abandonado. Uma formação livresca, enciclopédica, não dá conta de uma atuação profissional que terá que ser cotidianamente repensada, ou de uma prática que deverá ser sempre reavaliada. Mesmo que tenha se tornado um chavão, é necessário repetir que a pesquisa, nessa formação, não deve estar dissociada do ensino.

Ao mesmo tempo, torna-se necessário ao professor lidar com um conhecimento por si só definido enquanto provisório, fragmentário, não definitivo, e sem perspectiva de dar conta de uma totalidade.

Além disso, torna-se necessário também lidar com o diferenciado, o singular, como forma de apreender o social nas suas múltiplas dimensões. Frente a um movimento de massificação, impõe-se a necessidade de se lidar com a expressão de diferenças culturais, expressas enquanto diferença de gênero, classe social, nacionalidade, etnia, etc. Ou seja, lidar com o conhecimento numa sociedade em que ele é hierarquizado, e em que o sistema escolar se 
estrutura sobre uma concepção de saber/não saber que despoja os estudantes das classes populares até mesmo da sua historicidade.

Mais do que resolver, ou do que aderir a soluções prontas, o compromisso para o século XXI, para o professor de história, portanto, é justamente vivenciar essa crise. Perseguindo incessantemente um objeto que é, essencialmente, movimento - e essa busca é incessante porque é histórica - o professor se coloca no interior de um movimento de forças nas quais demandas por historicidade se digladiam com políticas visando a conformidade. Situar-se conscientemente no interior desse processo pode ser o grande desafio.

\section{Referências}

CABRINI, C., CIAMPI, H., VIEIRA, M. do P., PEIXOTO, M. do R., BORGES, V.H.P., 0 ensino de História na $5^{a}$ série : um desafio e uma tarefa urgente. Projeto História, $n^{\circ} 5$, São Paulo, novembro/1985.

CASTELO BRANC0, H. de A. Aula inaugural dos cursos de 1967 da Escola Superior de Guerra. Brasília: Mimeo, 1967.

FENELON, D. R. A questão dos Estudos Sociais, in Cadernos Cedes 10 - A prática de Ensino de História. São Paulo, CORTEZ, 1989.

GIORDAN, M.; STAROBINAS, L.; SCHWARTZ, G. Inclusão digital e reforma universitária. Folha de São Paulo, 29/03/2005, p. 3.

PCNEM. Bases Legais, p. 12. 